University of Nebraska - Lincoln

DigitalCommons@University of Nebraska - Lincoln

Faculty Publications, Department of Psychology

Psychology, Department of

October 2001

\title{
Just Deserts: An Experimental Study of Distributive Justice Norms
}

John T. Scott

University of California, Davis

Richard E. Matland

University of Houston

Philip A. Michelbach

University of California, San Diego

Brian H. Bornstein

University of Nebraska-Lincoln, bbornstein2@unl.edu

Follow this and additional works at: https://digitalcommons.unl.edu/psychfacpub

Part of the Psychiatry and Psychology Commons

Scott, John T.; Matland, Richard E.; Michelbach, Philip A.; and Bornstein, Brian H., "Just Deserts: An Experimental Study of Distributive Justice Norms" (2001). Faculty Publications, Department of Psychology. 185.

https://digitalcommons.unl.edu/psychfacpub/185

This Article is brought to you for free and open access by the Psychology, Department of at DigitalCommons@University of Nebraska - Lincoln. It has been accepted for inclusion in Faculty Publications, Department of Psychology by an authorized administrator of DigitalCommons@University of Nebraska - Lincoln. 
Published in American Journal of Political Science, Vol. 45, No. 4 (October 2001), pp. 749-767. Copyright (C) 2001 by the Midwest Political Science Association; published by Blackwell Publishing. Used by permission. http://www.blackwellpublishing.com/journal.asp?ref=0092-5853

\title{
Just Deserts: An Experimental Study of Distributive Justice Norms
}

\author{
John T. Scott University of California, Davis \\ Richard E. Matland University of Houston \\ Philip A. Michelbach University of California, San Diego \\ Brian H. Bornstein University of Nebraska-Lincoln
}

\begin{abstract}
We present a theoretically Informed experimental study of distributive justice norms concerning income distribution. Our study consists of three related experiments that examine how individuals use four distinct allocation principles derived from both normative and empirical researchequality, merit, need, and efficiency-under a condition of impartiality. Our experiments are designed to investigate these principles and to determine how independent factors influence how individuals use them. We find that individuals tend to use all or most of these principles simultaneously in making distributive justice judgments, but that they weigh them differently according to various factors. In particular, we find an expectedly strong difference between how women and men use and weigh these principles. This gender difference parallelsand may even underlie-the gender gap observed in political and policy preferences.
\end{abstract}

$\mathrm{U}$ nderstanding distributive justice norms is important for both normative and empirical research across political science and other disciplines. "What is justice?" has been a central question in political and moral theory for over two millennia. "Is it just?" is a question politicians, policy makers, and citizens face in deciding how to distribute benefits and burdens in society. Finally, the question "What do people believe is just?" interests researchers who study political behavior and attitudes. The legitimacy of the state and its leaders depends in large measure on their perceived justice (Weatherford 1992; Alwin, Gornev, and Khakhulina 1995), and legislation and public policy are judged in terms of their procedural and distributive justice (Rasinski 1987; Tyler et al. 1997).

Despite the importance of understanding distributive justice across all areas of social inquiry, a gap remains between normative and empirical approaches. Normative researchers tend to view empirical findings as irrelevant for their work. In response, Elster (1995) suggests that philosophical theories contradicted by experimental and other evidence are open to question. For their part, empirical researchers often focus on instrumental theories and downplay normative considerations. Justice research nonetheless shows that while self-interest is undoubtedly a factor in behavior, normative beliefs also matter (Tyler et al. 1997). Miller articulates the relevance of theoretically informed experimental research into distributive justice norms: the social scientist "needs a normative theory both to enable him to distinguish beliefs and pieces of behavior that express justice from those that do not, and to explain such beliefs and behavior adequately" $(1999,59)$.

John T. Scott is Associate Professor of Political Science, University of California, Davis, Davis, CA 95616-8682 (jtscott@ucdavis.edu). Richard E. Matland is Associate Professor of Political Science, University of Houston, Houston, TX 77204-3474 (matland@uh.edu). Philip A. Michelbach is a graduate student in Political Science, University of California, San Diego, La Jolla, CA 92093-0521 (pmichelb@weber.ucsd.edu). Brian H. Bornstein is Associate Professor of Psychology, University of Nebraska-Lincoln, Lincoln, NE 68588 (bbornstein2@unl.edu).

This study was funded by research grants from the National Science Foundation (SBR-9810243 and SBR-9810473). We would like to thank Robert Nemeth, Jennifer Mogg, and Christina Hughes for their assistance with collecting and entering data and Michael D. Martinez, Brian R. Sala, James F. Spriggs II, and Gregory Weiher for their comments and suggestions. 
Most research into distributive justice norms in political science has been done through public opinion surveys or interviews. This research often seems to show that individuals have conflicting views concerning justice (Lane 1962; Hochshild 1981; McClosky and Zaller 1984; Verba and Orren 1985; Kluegel and Smith 1986; Verba et al. 1987; Kluegel, Mason, and Wegener 1995). Reviewing the experimental and theoretical literature, Miller argues (1991, 377), however, that people may have complex rather than conflicting views on justice (see Hochshild 1981). Experimental research reveals that distributive justice judgments usually involve several distinct allocation principles. This research further shows that several factors influence how individuals use these principles, including what good is being distributed, the context of the distribution, and the individuals' particular characteristics, such as gender, culture, ideology, and socio-economic status. (For overviews, see Miller 1999; Törnblom 1992; Elster 1995; Tyler et al. 1997; Hegtvedt and Cook 1999).

We offer a theoretically informed experimental study of distributive justice norms concerning income distribution that examines both allocation principles themselves and the factors that affect how individuals use them. We investigate four allocation principles derived from both normative and empirical research-equality, merit, need, and efficiency-and examine how they are related to one another. We test how individuals use these allocation principles under the condition of impartiality, following a long tradition linking justice and impartiality (see Rawls 1971, Barry 1995). Our study builds on two recent studies of judgments of income distribution, the first by Frohlich and Oppenheimer (1992) and the second by Mitchell et al. (1993). Both studies show that individuals consider multiple principles and make tradeoffs among them, but they conflict as to which principles are involved. One of our aims is to make sense of these apparently contradictory results. Second, we examine how independent factors such as gender and ideology affect how individuals use these principles. In order to do so, we create more precise measures of participants' use of these principles and use a much larger sample size than previous studies.

We begin by discussing the four major allocation principles found in the normative research on distributive justice. Second, we review the relevant experimental research. Third, we present our own experimental design and theoretical predictions. Fourth, we present our results. Finally, we discuss our results concerning the allocation principles and the factors that influence how individuals use them. We take special note of an unexpect- ed gender difference in how women and men apply allocation principles and conclude by speaking to the relevance of our results for justice research and other areas of political science.

\section{Allocation Principles in Normative Theory}

From Aristotle to Rawls, philosophers have formulated different theories of distributive justice. The apparent disagreement over what is "just" or "fair" within philosophy nonetheless obscures a more important consensus over a small number of distinct allocation principles. We have identified four analytically distinct allocation principles in our review of the normative and empirical literature: equality, merit, need, and efficiency. Different theories of distributive justice can be categorized by which allocation principles they emphasize and how they conceptualize the relationship among them. For example, Rawls (1971) takes a "constructivist" approach that offers a theory of how individuals would lexically order these principles under a condition of "fairness" or impartiality. Other theorists adopt a pluralist approach that builds on an intuition that individuals use these principles simultaneously and make tradeoffs among them (Miller 1999) or that they weigh them differently in different "spheres" (Walzer 1983). Our aim is to draw on the normative literature to define these principles for systematic study.

\section{Equality}

The close relationship between equality and justice has been recognized since the beginnings of political philosophy. Aristotle indicates this kinship when he takes advantage of the fact that the same Greek word (isos) means both "fair" and "equal." "And so if what is unjust is unfair, what is just is fair [or: equal], as seems true to everyone even without argument" $(1985,123)$. While Aristotle emphasizes proportional equality between merit and reward, modern justice theories tend to disassociate equality and merit by conceiving of equality in an absolute sense. The norm of equality has been progressively expanded from arguments for equality of rights to equality of conditions (Dahl 1989). Equality remains the presumptive principle in nearly all modern theories of justice, as well as a central norm in debates over democracy, the social welfare state, and the distribution of income and other goods (Weale 1985). considerable disagreements over just what equality means remain (see Rae 1981, Sen 1992, ix, 12-16), but we will operationalize the principle as absolute equality of outcome. 


\section{Merit}

Despite the centrality of equality, most justice theories acknowledge other allocation principles that are potentially in tension with equality, notably merit. Merit requires that goods be distributed in proportion to contribution where that contribution is due to qualities or activities thought to "deserve" reward. Since contribution is usually unequal, merit is most often a justification for inequality. The idea of merit as proportionate equality has its roots in Aristotle's theory of proportional equality, or "equity." Merit claims have been questioned recently, most notably by Rawls, who argues that income outcomes based on effort and ability should be considered "arbitrary from a moral point of view" $(1971,15)$. Critics of Rawls and others nonetheless continue to argue that merit is a legitimate allocation principle (e.g., Sandel 1982; Sher 1987; Miller 1999). Moreover, empirical research shows people clearly do consider merit in making allocation judgments (Miller 1999, 63-73). Miller argues $(1999,66)$ the aspects of contribution that can be considered as "deserving" reward can be reduced to ability, effort, and performance. Since effort and ability are the normatively relevant determinants of performance, we consider merit in terms of effort and ability.

\section{Need}

If merit justifies departing from an equal distribution, need is often invoked as a principle to limit inequalities. For example, Boulding (1962) argues there is a tension between "desert" and a "social minimum." Need is closely related to equality, and equal need can be a criterion for equal distribution. A number of theories nonetheless treat need as a distinct allocation principle (see Miller 1999, 203-230). A similar tension might exist between need and efficiency, which justifies inequality based on the aggregate benefits. For example, Locke suggests that need places a limit on the inequality stemming from the exercise of property rights ([1689] 1988, 292-293). The principle of need as a "social minimum" has strongly influenced contemporary social democratic thought and social welfare programs in the United States and elsewhere (Marmor, Mashaw, and Harvey 1990). The concepts of need and relative deprivation have been developed in welfare economics as important elements in the analysis of income distribution (especially Sen 1992, 1997)) but there has been little systematic development of need as a normative principle (Braybrooke 1987). This lack of theoretical development may be due in part to the strong conceptual relationship between need and equality, especially when need is con- ceived of as relative rather than absolute. Since one of the aims of our experiment is to test the distinctness of need and equality, we consider need in absolute terms as a minimum level of necessary social goods.

\section{Efficiency}

Efficiency is another allocation principle used to justify inequalities in terms of aggregate benefit (Locke [1688] 1988; Schumpeter 1947; Friedman 1963). While not strictly speaking a normative principle in itself, efficiency is used to justify the fairness of inequalities and therefore raises a normative consideration in allocation judgments. There is a tension between claims for economic efficiency and the strong claim to equality. Rawls terms (1971, $36,44)$ this tradeoff the "aggregative-distributive dichotomy," while Okun (1975) makes it the centerpiece of his work. Many theorists reject merit as a legitimate justification of inequality, but defend inequalities as legitimate when based upon efficiency (Nozick 1974; Okun 1975; Hayek 1976). We use the term "efficiency" to mean that a greater amount of overall goods for the same amount of input is preferred (see Sen 1992, especially 6-8)) or what is sometimes termed "wealth maximization" (Plattner 1979, 43-44; Posner 1981). ("Efficiency" as we operationalize it does not meet the Pareto optimality condition, but it is consistent with the Kaldor-Hicks principle.) Our research is designed to explore the relationship between efficiency and the other allocation principles.

\section{Experimental Research on Distributive Justice}

The allocation principles we identify in the normative literature are also central to experimental research on distributive justice. Experimental research over the past fifty years, principally in psychology, has been characterized by a shift to a pluralist framework based on findings that individuals use several allocation principles in distributive justice judgments. Early research concentrated on equity theory, which conceived distributive justice in terms of the proportion of inputs and outputs from an interaction (e.g., Adams 1965; Messick and Cook 1983). The pluralist approach was inspired largely by Deutsch, who argues $(1975,1985)$ that equity research conflates distinct allocation principles. Most subsequent research has settled upon a limited number of allocation principles, although terminological inconsistency and theoretical incompleteness continues to impede both progress and communication. Deutsch (1975) identifies three distinct principles: equity, equality, and need. 
What he means by "equity" is the desire for higher aggregate outputs, or "efficiency" in our terminology. Similarly, Schwinger (1980) studies contribution, equality, and need, but by "contribution" he means deserts proportional to contribution, or "merit" in our usage. A similar pluralist approach can be seen in other empirical research into distributive justice. For instance, the study of public opinion on justice issues conducted by the International Social Justice Program in twelve countries finds principles roughly similar to those we have discussed through factor analysis of survey responses (Swift et al. 1995). Finally, Sen $(1997,15-18,77,91)$ utilizes these same principles in his research on welfare economics. Our review of the normative and empirical research is intended to be a step toward a more comprehensive theoretical basis for empirical study.

Theoretical incompleteness may also explain the apparently inconsistent results found in two recent experimental studies that are particularly relevant for our own work. In the first study, Frohlich and Oppenheimer (1992) present an empirical test of Rawls' theory of justice by having participants in groups determine rules for distributing income they are to earn by doing an unspecified task (behind a "veil of ignorance"). Their results show a striking consistency through different iterations and in different settings, including cross-nationally (Frohlich and Oppenheimer 1992, especially 60). Of the four alternative models among which groups choose, they find that groups almost never choose a Rawlsian solution (1 percent), and relatively seldom do they choose either maximizing average income (12 percent) or maximizing efficiency with an inequality ("range") constraint (9 percent). Instead, groups overwhelmingly choose maximizing income after setting a minimum ("floor") income (78 percent). They argue their results reveal that efficiency and need (in our terminology) are the chief principles used in adopting fair income distributions. Their results are nonetheless open to different interpretations. The consistent adoption of a floor constraint may offer evidence that need is a distinct principle, but it might also be interpreted as evidence for a concern with inequality. While relatively few groups explicitly chose a range constraint, many chose a minimum income level that effectively narrowed the income range, especially since the minimum levels they adopted were in several cases well above real-world income levels (1992, 82-94; cf. Lissowski and Swistak 1995). Likewise, while their finding that most groups maximized income may indicate a concern with efficiency, since they did not distinguish between efficiency and merit in their design they cannot determine why groups allowed inequality when maximizing income.
The second study by Mitchell et al. (1993) produces results that seem to contradict Frohlich and Oppenheimer's. They also examine behavior under a condition of impartiality, but rather than attempting to place individuals behind a "veil of ignorance," they tell participants to assume they are being asked their opinion about policy options as advisors to a hypothetical society. They then have participants rank these policy options in the form of income distributions that pose tradeoffs between equality and efficiency. Their major experimental manipulation is to vary information given to participants about the degree that merit explains income (10 percent, 50 percent, or 90 percent), as opposed to luck, connections, and similar factors. Their results demonstrate that participants employ both equality and efficiency and make tradeoffs between them. Their results further suggest that equality-efficiency preferences are mediated by assumptions about merit, with participants showing an increased preference for efficiency and a decreased preference for equality as the degree of assumed merit increases. They claim that the result of the merit manipulation supports Rawls, since participants tend to prefer equality over efficiency when luck and other "morally arbitrary" factors overwhelmingly determine income. This result may confirm that individuals act in a manner consistent with Rawls' expectations when they believe that unequal income is not in itself merited, but their results otherwise contradict Rawls since considerations of merit clearly affected participants' relative preference for equality in conditions where merit increasingly predicts income. Likewise, their claim that a significant number of participants have behavior consistent with a Rawlsian maximin model is questionable because their a priori model specification does not effectively distinguish egalitarian and Rawlsian solutions: if they had used relative equality as their measure for equality (i.e., the proportion between the highest and lowest quartiles) rather than the absolute measure they did employ (i.e., the absolute dollar difference between the highest and lowest quartiles), then the rank ordering for the egalitarian model would be exactly the same as the Rawlsian model. Although the measurement of inequality is a complex and often highly technical subject (see Temkin 1993; Sen 1997), all major measures are proportional rather than absolute, and therefore we use a proportional measure in our own experiments. Finally, it is unclear from Mitchell et al.'s results whether need operates as a distinct allocation principle since they did not systematically vary need independent of equality. Subsequent work by two of the authors of their study points out this flaw and suggests that participants are in fact influenced by 
need (Ordóñez and Mellers 1993). We vary need independent of equality.

Our own research is intended in part to test the seemingly conflicting results of these two sets of experiments. To summarize: whereas Frohlich and Oppenheimer (1992) find virtually no support for either Rawlsian or egalitarian norms, and instead find that participants overwhelmingly maximize efficiency after setting a minimum level of need, Mitchell et al. (1993) argue their results show strong Rawlsian and egalitarian norms at work as well as a concern for efficiency. Some of the differences in the findings of these experiments are undoubtedly due to differences in experimental manipulation. We further suggest that they are the result of an incomplete experimental design that prevents either set of studies from analyzing all four allocation principles simultaneously. Our experimental design builds on that of Mitchell et al., but with significant changes based on our review of the normative and experimental research.

\section{Experimental Design and Theoretical Predictions}

\section{Experimental Design}

All three experiments in our study employ the same basic design. Participants read a short description of a hypothetical society and are asked to imagine they are outside observers giving their advice to the society. To insure impartiality, they are explicitly told they are not members of this society. They are asked to evaluate nine policy alternatives being considered by this society based on the effects each would have on the level and distribution of income (see appendix for participant instructions). These policies are not described, but are presented in terms of their effect on income. After reading the country description, participants are given a short test to confirm that the experimental manipulations were successful. ${ }^{1}$ We then present participants with a set of nine income distributions in randomized fashion. For each distribution a bar graph shows the average income for each quintile and information on the overall average income, the ratio of the incomes of the top and bottom quintiles (the "income inequality ratio"), and the poverty line. Participants evaluate each distribution on a scale

\footnotetext{
${ }^{1}$ Participants who do not answer all these questions correctly or do not complete the experiment are not included in the final data set. In order to insure that they have been successfully manipulated by the between-subject merit and need variables, the manipulation check includes questions on the degree to which income is determined by effort and ability and the level of the poverty line. It also contains questions to make sure that participants can distinguish between more efficient and more equal income distributions.
}

from 0 ("very bad") to 10 ("very good"). The answers to these questions are used to create the dependent variables for statistical analyses. Finally, participants complete a post-experimental questionnaire that provides the basis for the control variables.

\section{Experimental Manipulations and Dependent Variables}

Within each experiment, we present all participants with the same set of nine income distributions. These nine alternatives result from the manipulation of two withinsubject variables, each with three levels: efficiency (low, medium, high) and equality (high, medium, low). Efficiency is operationalized as average income and equality as the ratio of the income of the highest quintile to the lowest. Table 1 shows the general design used for all three experiments along with the income distributions used in Experiments 1 and 2. In all three experiments we vary efficiency in three levels by increasing average income constantly from one level to the next: $\$ 32,000$, $\$ 42,000, \$ 55,000 .^{2}$ We also vary equality across three levels in all the experiments. Varying equality and efficiency in this way poses participants with a number of equality-efficiency tradeoffs that we can use to determine their relative preferences for the two principles. In Experiments 1 and 2, participants face four equality-efficiency tradeoffs, represented by the arrows along the diagonals in Table 1. For example, there is a tradeoff between the high equality/medium efficiency distribution and the medium equality/high efficiency one. Each tradeoff enables us to examine whether participants prefer greater income at the cost of lower equality or whether they prefer greater equality at the cost of lower income.

We study the relationship between equality-efficiency preferences and the other two allocation principles, merit and need, through two variables manipulated between participants. The first variable is designed to examine how equality and efficiency preferences are affected by assumptions about merit. As in Mitchell et al. (1993), we randomly vary what participants are told about the degree to which income is explained by effort and ability (10 percent, 50 percent, and 90 percent) as opposed to luck, connections, and similar factors. The second variable is designed to test whether need is a

\footnotetext{
${ }^{2}$ When creating the income distributions we consulted U.S. Census Bureau data in order to make the distributions plausible. In all of our experiments the middle efficiency level is $\$ 42,000$ for the average income of a four-person family (our stipulated measure). The median income (averaged for the two testing sites) for a four-person family for fiscal year 1998 was $\$ 42,709$. See http://www.census.gov/hhes/income/ 4person.html .
} 
TABLE 1 Income Distributions for Experiments 1 and 2

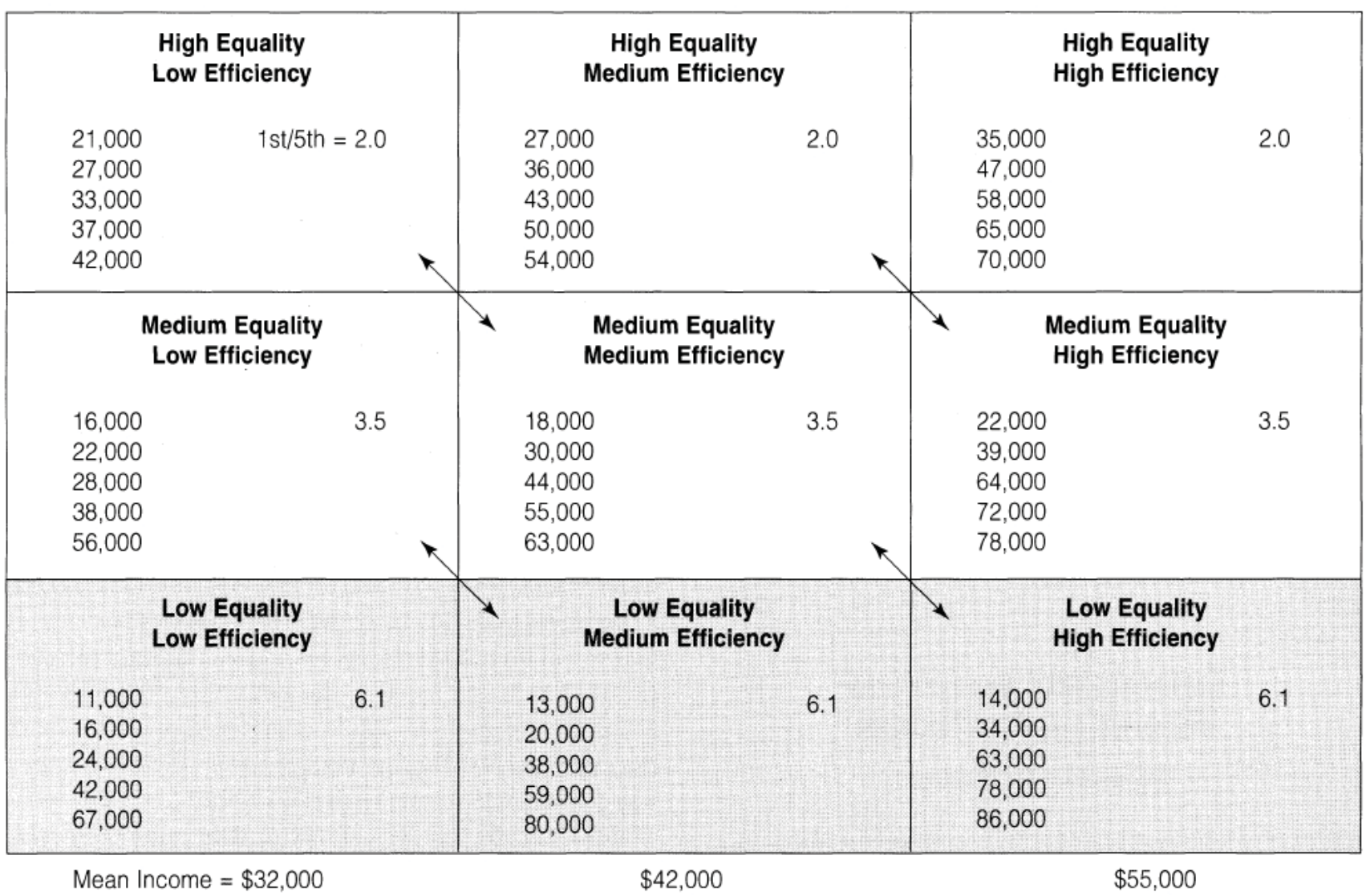

distinct allocation principle. We do so by manipulating what participants are told about the poverty line. In Experiments 1 and 3 , the poverty line is either $\$ 10,000$ or $\$ 15,000{ }^{3}$ The poverty line manipulation affects the low equality distributions, or the bottom, shaded row in Table 1 . When the poverty line is stipulated as $\$ 10,000$, all of the income quintiles in the three low equality income distributions are above the poverty line, but when the poverty line is stipulated as $\$ 15,000$, the lowest income quintile in the three low equality income distributions is below the poverty line.

We have developed two dependent variables to observe the relationships among the different allocation principles. The first dependent variable is an equalityefficiency tradeoff score created by summing the differences between a participant's ratings of the two distributions in each of the four diagonal tradeoffs indicated by the arrows in Table 1 (e.g., high equality/low efficiency -medium equality/medium efficiency). Preferences for

\footnotetext{
${ }^{3}$ We consulted U.S. Census Bureau data when designing the poverty manipulation, although we were constrained in setting our poverty line by its effect on the income distributions we adopted. The federally stipulated poverty line for a four-person family was $\$ 16,400$ in 1997 . See http://www.census.gov/hhes/poverty/threshld97.html.
}

equality result in positive scores, while preferences for efficiency produce negative scores. The second dependent variable is a need sensitivity score created by taking the sum of a participant's ratings of the three distributions affected by the poverty manipulation, i.e., the three low equality distributions in the bottom, shaded row in Table 1.

Participants were undergraduates at the University of Houston and Louisiana State University, all of whom were tested in Fall 1998. Participants from the University of Houston were tested in lower-level political science courses, while participants from Louisiana State University were recruited in lower-level psychology courses and tested in small groups in a laboratory setting. No statistically significant differences exist between the two sites or among testing groups, so we combine the data for all analyses.

\section{Theoretical Predictions}

Equality-efficiency preferences. Our manipulation of equality and efficiency levels in the income distributions is designed examine participants use and efficiency as allocation principles, especially in relation to one anoth- 
er. By varying equality and efficiency levels, we can test whether efficiency and equality are "normal goods," in the economic sense of more being preferred to less. If equality functions as a normal good, then participants' ratings of more equal income distributions will be higher than less equal distributions within each efficiency level. Likewise, if efficiency is a normal good, then they will prefer more efficient distributions to less efficient ones within each equality level. If, as we expect, most participants use both equality and efficiency as allocation principles, then the interesting question becomes how they make tradeoffs between them.

We begin our analysis of participants' equality-efficiency tradeoffs by categorizing individual-level behavior in accordance with three alternative theoretical models: (1) strict egalitarian; (2) strict efficiency-maximization; (3) mixed. Strict egalitarians always prefer the more equal distribution to the less equal one in each of the four diagonal equality-efficiency tradeoffs indicated by the arrows in Table 1. In contrast, strict efficiencymaximizers always prefer the more efficient distribution to the less efficient one in the same four tradeoffs. Finally, participants who view both equality and efficiency as normal goods will make tradeoffs between them, sometimes preferring more efficient distributions and sometimes more equal distributions, depending upon their relative preferences for the two principles. We expect most participants to use both equality and efficiency as allocation principles, viewing both equality and efficiency as normal goods and therefore making tradeoffs between them. We also expect they will use these two principles to different degrees, with some participants more concerned with equality and others with efficiency. These results would be consistent with Mitchell et al.'s (1993) findings, but generally contrary to Frohlich and Oppenheimer's (1992) results.

While inspection of the raw data and comparison of participants' behavior to these theoretical models provide us with considerable information, we will analyze equality-efficiency preferences more closely by using the equality-efficiency tradeoff score as the dependent variable in multivariate analyses. This variable allows us to examine the interaction of equality-efficiency preferences with the independent merit and need variables in the presence of the control variables.

Merit effects. The merit manipulation is designed to test whether equality and efficiency preferences are mediated by assumptions about the degree to which income is explained by effort and ability, or "merited." We randomly divide the sample for each experiment into three groups that are given different information about the degree to which income is merited: 10 percent, 50 percent, and 90 percent. The merit factor identifies which group a participant falls into $(10,50,90)$. We predict that participants will be less concerned with equality as the degree to which income is merited increases. The merit factor should therefore have a negative effect on the equalityefficiency tradeoff variable. This result would be consistent with Mitchell et al. (1993). We further expect that merit should have a negative effect on the need sensitivity variable since participants will view those below the poverty line as increasingly "deservedly" poor. This finding would be consistent with the tradeoff Ordóñez and Mellers (1993) find between need and merit.

Need effects. The poverty-line manipulation is designed to determine whether need is a distinct allocation principle. As noted above, the design used by Mitchell et al. (1993) makes it impossible to determine whether a preference for more egalitarian distributions is due to a concern with equality or need. Our poverty-line manipulation enables us to distinguish the two principles. We randomly divide our sample into two groups with different poverty lines: $\$ 10,000$ (where no distributions are affected) and $\$ 15,000$ (where the low equality distributions are affected). The poverty dummy variable identifies which group a participant falls into $(0$ if the participant is in the $\$ 10,000$ group and 1 in the $\$ 15,000$ group). We expect that participants will give lower ratings to distributions affected by the poverty manipulation across merit conditions, with the poverty variable therefore having a negative effect on the need sensitivity variable. The distinctness of need as an allocation principle would be consistent with several studies, including Frohlich and Oppenheimer (1992; see also Alves and Rossi 1978; Mellers 1982; Ordóñez and Mellers 1993). We also expect the poverty line to have a weak effect on the equality-efficiency tradeoff variable since a concern with need should affect two of the four equations that comprise the variable.

Control variable effects. Our post-experimental questionnaire elicits information on demographic and political values that provide measures for the control variables that other studies have suggested affect how individuals use allocation principles in making distributive justice judgments. A number of studies show differences in the justice beliefs of men and women. Women generally tend to prefer equality, while men tend to weigh efficiency more heavily (Major and Deaux 1982; Major and Adams 1983; Kluegel and Smith 1986, chapter 5). In ad- 
dition, women have been found to be more sensitive to poverty and need (Kluegel and Miyano 1995; Davidson, Steinmann, and Wegener 1995). We therefore predict that gender will have a negative effect on the equalityefficiency tradeoff and need sensitivity variables.

Political ideology has also been found to affect distributive justice judgments, with liberals on average being more concerned with equality and conservatives with efficiency (Tetlock and Mitchell 1993; Mitchell et al. 1993). Similarly, conservatives are less concerned with need than liberals, especially as merit level increases (see Skitka and Tetlock 1992, 1993; Tetlock and Mitchell 1993). We therefore expect that ideology (based on a five-point scale from conservative to liberal) will have a positive effect on the equality-efficiency tradeoff variable and a negative effect on the need sensitivity variable.

While most studies suggest that lower SES individuals in the United States generally endorse disparity in income based on beliefs in merit (Lane 1962, chapter 5; Hochshild 1981), a negative correlation has been found between SES and egalitarian beliefs (Lane 1962, chapter 7; Davidson, Steinmann, and Wegener 1995), and a positive correlation has been found between high SES and merit beliefs (McClosky and Zaller 1984; Kluegel and Smith 1986). No experimental research has been done to test these findings.

Finally, we include a question designed to test the power of our experimental manipulation of merit. It is possible that the degree to which participants see income as being deserved is not a function of the experimental manipulation of merit level in a hypothetical society, but rather their perceptions of our own society. To test for this possibility, we ask participants for their own perception of the degree to which income is merited in the United States $(0-100$ percent). If this independent merit perception variable is not significant in our analyses, then we can be confident that our results concerning the effect of merit on equality-efficiency preferences are due to our experimental manipulation and not to individuals' independent perceptions.

\section{Results}

\section{Experiment 1}

In Experiment 1, the income distributions rated by participants were created by manipulating efficiency and equality independently. We increase, efficiency constantly across three levels $(\$ 32,000, \$ 42,000, \$ 55,000)$ and increase income inequality constantly across three levels
$(2.0,3.5,6.1)$. The income distributions used in Experiment 1 are shown in Table 1 above. Table 2 reports the mean ratings for the income distributions for the three merit conditions and separated by the two poverty conditions. There are 401 participants in Experiment 1 (242 women and 159 men).

Our expectation that participants would generally treat both equality and efficiency as normal goods is confirmed by the mean ratings in Table 2 . In every single case across all conditions participants on average prefer more equal to less equal distributions when efficiency is held constant and more efficient to less efficient distributions when equality is held constant.

More interestingly, individual-level analysis of the ratings shows that participants are divided in their use of equality and efficiency. Their differing use of principles can be seen by comparing participants' observed behavior to the theoretical models outlined above. The strict egalitarian model fits the observed behavior of 26.2 percent of participants, while the strict efficiency model fits the behavior of 7.7 percent of participants. Only one-third of participants are therefore strongly oriented toward either equality or efficiency, while the other two-thirds fit the mixed model, using both equality and efficiency as allocation principles and making tradeoffs between them.

Experiment 1 initially seems to confirm that participants' equality-efficiency preferences are mediated by their merit assumptions. First, simply using visual inspection of the mean ratings and focusing on the diagonal tradeoffs, as Mitchell et al. (1993) do, we see an apparent shift in preferences in the aggregate results. The direction of the absolute preferences in the four diagonal tradeoffs are shown by arrows superimposed over the mean ratings in Table 2, with arrows pointing in a single direction indicating a statistically significant difference (two-tailed test; $p<.05$ ). Inspection reveals that equality-efficiency preferences change in the direction of preferring more efficiency as merit increases. When merit is set at 10 percent, seven of the eight tradeoffs show a clear preference for more equality, while when merit is set at 90 percent there is an even split with participants on average preferring greater efficiency in four of the tradeoffs and greater equality in the other four. These results are consistent with Mitchell et al. (1993), but we have developed more precise measures to explore these apparent preference changes more fully.

We analyze equality-efficiency preferences using the equality-efficiency tradeoff score described above. Equality-efficiency tradeoff scores ranged from +24 (out of a possible +30 ), for the participant with the most extreme preference for equality, to -28 (out of a possible 
TABLE 2 Mean Ratings of Income Distributions in Experiment 1

\begin{tabular}{|c|c|c|c|c|c|c|c|c|}
\hline \multicolumn{9}{|c|}{$\$ 10,000$ Poverty Line Condition } \\
\hline \multicolumn{3}{|c|}{$10 \%$ Merit Condition } & \multicolumn{3}{|c|}{$50 \%$ Merit Condition } & \multicolumn{3}{|c|}{ 90\% Merit Condition } \\
\hline 5.94 & 6.87 & 8.29 & 5.68 & 6.93 & 8.47 & 4.95 & 6.22 & 7.54 \\
\hline 4.60 & 5.37 & 5.94 & 4.71 & 5.53 & 6.63 & 4.44 & 5.51 & 6.61 \\
\hline 1.43 & 2.43 & 3.14 & 1.90 & 2.97 & 3.15 & 2.43 & 3.62 & 4.27 \\
\hline \multicolumn{3}{|c|}{$N=63$} & \multicolumn{3}{|c|}{$N=59$} & \multicolumn{3}{|c|}{$N=63$} \\
\hline \multicolumn{9}{|c|}{$\$ 15,000$ Poveriy Line Condition } \\
\hline \multicolumn{3}{|c|}{$10 \%$ Merit Condition } & \multicolumn{3}{|c|}{$50 \%$ Merit Condition } & \multicolumn{3}{|c|}{$90 \%$ Merit Condition } \\
\hline 5.48 & 7.20 & 8.78 & 5.61 & 7.11 & 8.33 & 4.81 & 6.20 & 7.69 \\
\hline 3.95 & 5.50 & 6.32 & 4.20 & 5.51 & 6.51 & 4.62 & 6.16 & 7.57 \\
\hline 1.68 & 2.53 & 3.17 & 1.66 & 2.15 & 3.13 & 2.24 & 3.02 & 4.13 \\
\hline \multicolumn{3}{|c|}{$N=60$} & \multicolumn{3}{|c|}{$N=61$} & \multicolumn{3}{|c|}{$N=62$} \\
\hline
\end{tabular}

$-30)$, for the participant with the most extreme preference for efficiency $(x=+3.4, s d=8.8)$. The two independent variables of greatest interest are merit level and poverty level. Political ideology, mother's education (our measure of SES), ${ }^{4}$ sex, and the participant's independent merit perception are used as control variables ${ }^{5}$ Table 3a presents the results of regressing these factors on the equality-efficiency tradeoff score.

The aggregate results reported in Table 3a (column 1) show merit level has a strong effect on equality preferences in the expected direction. As the degree to which income is explained by effort and ability increases, participants clearly become less concerned with equality. The poverty variable does not appear to have an effect, but we will examine the poverty line manipulation momentarily. As for the control variables, sex has a large effect. Women show a much stronger preference for equality than men. Furthermore, SES has an effect, with participants from higher-SES families tending to emphasize efficiency. Finally, that independent merit perception is not statistically significant suggests that participants' behavior is explained by our experimental manipulation of merit rather than their own preconceptions. ${ }^{6}$

${ }^{4}$ We tested four different measures of SES: mother's education, father's education, family income, and a factor created using all three elements. All four measures provide consistent effects. We chose mother's education as the control variable because we have more complete data on this variable.

${ }^{5}$ We ran regression models for all analyses that included measures for party identification, race, and age. None of these other variables had any statistically significant effect or had any substantial influence on the statistically significant variables, and so we report only results of the reduced regression equation.
The gender difference we found on the aggregate level is particularly striking, and we therefore divided the sample into women and men and reran the regressions on these separate samples. Table 3 a (columns 2 and 3) shows the results for women and men. We find that a surprisingly large difference in the way men and women respond to the experimental stimuli underlies the aggregate results. First, the significant effect of the merit manipulation seen in the aggregate results was driven by women, who react strongly to the change in merit while men do not. Second, while ideology does not have an effect on the aggregate level, dividing the sample reveals a strong effect for men but no effect for women. Among men, liberals tend to be more egalitarian while conservatives are more concerned with efficiency. As for SES, men are somewhat more strongly affected by SES, with higher-SES participants more concerned with efficiency. The effect of SES for women is in the same direction as for men, although the variable is not statistically significant. Finally, participants' independent merit perception is not significant for either women or men.

We analyze the distinctness of need by examining the effect of poverty manipulation on participants' ratings of the income distributions affected by the manipulation. We use the need sensitivity score as the depen-

\footnotetext{
${ }^{6} \mathrm{I}$ ndependent merit perceptions in Experiment 1 varied from 5 percent to 100 percent, with a mean of $61.7(s d=19.8)$. Results for Experiments 2 and 3 were very similar. For Experiment 2, they varied from 0 percent to 100 percent, with a mean of $64.6(s d=17.5)$. For Experiment 3 , they varied from 0 percent to 100 percent, with a mean of 62.2 $(s d=20.7)$.
} 
TABLE 3 Results of Regression Analyses for Experiment 1

\begin{tabular}{|c|c|c|c|c|c|c|}
\hline \multirow{3}{*}{$\begin{array}{l}\text { Dependent Variable: } \\
\text { Independent Variables }\end{array}$} & \multicolumn{3}{|c|}{$\begin{array}{c}\text { A } \\
\text { Equality-Efficiency Preferences }\end{array}$} & \multicolumn{3}{|c|}{$\begin{array}{c}\text { B } \\
\text { Need Sensitivity } \\
\end{array}$} \\
\hline & \multicolumn{3}{|c|}{ Equality-Efficiency Tradeoff Score } & \multicolumn{3}{|c|}{ Need Sensitivity Score } \\
\hline & Aggregate & Women & Men & Aggregate & Women & Men \\
\hline Merit Factor $(10,50,90)$ & $\begin{array}{l}-.054^{\star \star \star} \\
(.014)\end{array}$ & $\begin{array}{l}-.078^{\star * \star} \\
(.016)\end{array}$ & $\begin{array}{l}-.018 \\
(.025)\end{array}$ & $\begin{array}{l}.033^{* *} \\
(.010)\end{array}$ & $\begin{array}{l}.051^{\star \star \star} \\
(.012)\end{array}$ & $\begin{array}{l}-.007 \\
(.017)\end{array}$ \\
\hline Poverty Factor $(0,1)$ & $\begin{array}{l}-.23 \\
(.87)\end{array}$ & $\begin{array}{l}.007 \\
(.98)\end{array}$ & $\begin{array}{c}-.23 \\
(1.64)\end{array}$ & $\begin{array}{l}-.85 \\
(.61)\end{array}$ & $\begin{array}{c}-1.26^{*} \\
(.72)\end{array}$ & $\begin{array}{c}-.42 \\
(1.08)\end{array}$ \\
\hline Gender $(0=$ man; $1=$ woman $)$ & $\begin{array}{l}4.18^{\star \star \star} \\
(.90)\end{array}$ & & & $\begin{array}{l}-2.02 \text { ** } \\
(.65)\end{array}$ & & \\
\hline Ideology (1-5; 1 = strong conservative) & $\begin{array}{l}.85 \\
(.54)\end{array}$ & $\begin{array}{l}.13 \\
(.65)\end{array}$ & $\begin{array}{l}1.68^{*} \\
(.94)\end{array}$ & $\begin{array}{l}-.47 \\
(.35)\end{array}$ & $\begin{array}{l}-.42 \\
(.41)\end{array}$ & $\begin{array}{l}-.50 \\
(.59)\end{array}$ \\
\hline $\begin{array}{l}\text { Mother's Education } \\
(0-5 ; 0=\text { less than high school) }\end{array}$ & $\begin{array}{l}-.68 * \\
(.28)\end{array}$ & $\begin{array}{l}-.42 \\
(.31)\end{array}$ & $\begin{aligned}-1.03^{*} \\
(.52)\end{aligned}$ & $\begin{array}{l}.13 \\
(.20)\end{array}$ & $\begin{array}{l}-.11 \\
(.23)\end{array}$ & $\begin{array}{l}.44 \\
(.35)\end{array}$ \\
\hline $\begin{array}{l}\text { Independent Merit } \\
\text { Perception (0-100\%) }\end{array}$ & $\begin{array}{l}-.011 \\
(.023)\end{array}$ & $\begin{array}{l}-.011 \\
(.027)\end{array}$ & $\begin{array}{l}-.023 \\
(.040)\end{array}$ & $\begin{array}{l}.000 \\
(.017)\end{array}$ & $\begin{array}{l}-.015 \\
(.020)\end{array}$ & $\begin{array}{l}.026 \\
(.028)\end{array}$ \\
\hline Constant & $\begin{array}{l}3.43 \\
(2.68)\end{array}$ & $\begin{array}{l}10.17 \\
(3.06)\end{array}$ & $\begin{array}{r}.89 \\
(4.75)\end{array}$ & $\begin{array}{l}9.41^{* * *} \\
(1.94)\end{array}$ & $\begin{array}{l}8.05^{* * *} \\
(2.25)\end{array}$ & $\begin{array}{l}7.84^{*} \\
(3.28)\end{array}$ \\
\hline $\begin{array}{l}\text { Adjusted R2 } \\
N\end{array}$ & 364.104 & .089 & .030 & .072 & 102 & .032 \\
\hline
\end{tabular}

Note: ${ }^{*} p<.05,{ }^{* *} p<.01,{ }^{* \star *} p<.001$, two-tailed test; OLS standard errors in parentheses for equality-efficiency preference analyses and robust standard errors in parentheses for need sensitivity analyses.

dent variable and the same independent variables as in the regression analyses of equality-efficiency preferences. ${ }^{7}$ The results of the analyses of need are reported in Table 3b. The aggregate results (column 1) show the poverty factor has an effect in the expected difference, but it is not statistically significant. The only statistically significant variables are merit and sex. Women give lower ratings to the low equality distributions than men regardless of the poverty line. As with the previous analyses, we split the sample by gender and reran the analysis. When we look at the results for women alone (column 2), we see some support for the distinctness of need from the marginal statistical significance of the poverty manipulation. Women's concern with need is also mediated by the merit manipulation, with women being less

\footnotetext{
${ }^{7}$ In running regression diagnostics, we found heteroskedasticity across the error terms of the standard OLS regression. We therefore report robust standard error estimators using the Huber-White correction. We also ran the analyses using a negative binomial regression. Even though the dependent variable is not, strictly speaking, an event count, the shape of the underlying distribution conforms to a negative binomial. The results in terms of the significance of the independent variables are the same no matter which method we use (standard OLS, OLS with robust standard error estimators, or negative binomial regression).
}

concerned about need as the degree to which merit explains income increases. In turn, men (column 3) do not appear to use need as a distinct allocation principle, and none of the variables tested predict men's need sensitivity.

While we were surprised that the poverty manipulation did not have a stronger impact, we suspect that this result may be due in part to a serious floor effect. Scores for the low equality distributions were already so low on average that the added poverty condition had only a limited effect. For example, where the poverty line was set at $\$ 10,000,33$ percent of participants gave the low equality/low efficiency distribution a rating of 0 and 21 percent gave it a rating of 1 . We further believe that our design of the income distributions in Experiment 1 did not sufficiently distinguish need from inequality since the three income distributions affected by the poverty line manipulation were also the lowest equality level distributions. We therefore believe that the concern for low equality in those distributions masked any distinct sensitivity to need. In order to test this conjecture, we did a follow-up experiment, Experiment 2. 


\section{Experiment 2}

For Experiment 2 we use the same design and distributions as Experiment 1 (see Table 1), but with the poverty line stipulated as $\$ 20,000$. In addition to the three distributions in the low equality level, as in Experiment 1, raising the poverty line to $\$ 20,000$ affects the two distributions with low and medium efficiency levels in the medium-equality row, placing the bottom quintile of these distributions below the poverty line. Because the level of inequality of these distributions is modest, we believe this to be a better test of the poverty line manipulation as it avoids confounding concern for inequality with sensitivity to need, as we suspect occurred in Experiment 1. We expect that the mean ratings for these two distributions will be significantly lower in the $\$ 20,000$ poverty condition than in the $\$ 10,000$ and $\$ 15,000$. Experiment 2 includes 136 participants (eighty-five women and fifty-one men).

To analyze the effect of the poverty manipulation in Experiment 2, we use a modified need sensitivity index that creates a score for each participant by summing the ratings of the two distributions in the medium equality level affected by the poverty manipulation. We then use the modified need sensitivity score as the dependent variable and control for the same variables as in the previous analyses, combining the $\$ 20,000$ poverty condition cases of Experiment 2 (poverty variable coded 1) and the $\$ 10,000$ and $\$ 15,000$ conditions from Experiment 1 (poverty variable coded 0 ).

The results for Experiment 2 using the modified need sensitivity score show more support than Experiment 1 for the existence of need as a distinct allocation principle. On the aggregate level the poverty factor is a highly statistically significant predictor of participants' need sensitivity $(\mathrm{b}=-1.03 * * *(.25))$. As with Experiment 1 , merit is a relatively strong predictor $(b=.012 * *$ (.005)), with participants less concerned with need as merit level increased. When we separate the sample into women and men, as in the previous analyses, we see the same gender difference as in the previous experiment. For women, the poverty factor is strongly statistically significant $(b=-1.48 * * *(.41))$. The merit factor is also a statistically significant predictor for women (b $\left.=.015^{* *}(.006)\right)$, as is ideology $\left(\mathrm{b}=-.49^{* *}(.25)\right)$, with liberals being somewhat more concerned with poverty than conservatives. As for men, the poverty factor is not statistically significant in predicting need sensitivity, nor is any other variable. ${ }^{8}$

\footnotetext{
${ }^{8}$ These results use a two-tailed test, ${ }^{*} \mathrm{p}<.05,{ }^{* *} \mathrm{p}<.01,{ }^{* * *} \mathrm{p}<$ , 001 , with standard errors in parentheses. Regression diagnostics revealed no heteroskedasticity so we use OLS standard errors. Testing for the effect of the $\$ 20,000$ poverty line on the three low-equality distribu-
}

In sum, Experiment 2 suggests need is a distinct allocation principle for at least some participants and that women are considerably more sensitive to need than men. It also seems to confirm our conjecture from the results of Experiment 1, that need and equality are often difficult to distinguish in practice although they are conceptually distinct. One of the purposes of Experiment 3 is to clearly distinguish need and equality to see whether the principles function independently.

\section{Experiment 3}

Experiment 3 is designed to explore equality-efficiency preferences in greater detail, as well as to confirm the results of Experiments 1 and 2 under different conditions. The equality-efficiency tradeoffs in Experiment 1 were limited to the four diagonal cases between two constant equality levels. Our analysis of individual-level behavior in Experiment 1 likely overstated the number of efficiency-maximizers and egalitarians, and therefore underestimated the number of participants who use both principles. In Experiment 3 we create more tradeoff situations to refine our analysis of participants' use of equality and efficiency as allocation principles. This change in design will also alter the effect of the poverty manipulation on the low equality income distributions, making the issue of need more distinct than in the earlier experiments.

As in the previous experiments, we increase efficiency using the same three constant levels $(\$ 32,000$, $\$ 42,000, \$ 55,000)$. While we use three equality levels as the earlier experiments, rather than keeping equality constant we decrease equality from distribution to distribution across efficiency levels in approximately equal (absolute) steps within each equality level. This variation of equality means that participants are posed with two horizontal equality-efficiency tradeoffs within each equality level (e.g., high equality/medium efficiency versus high equality/high efficiency), or six horizontal tradeoffs in all, in addition to the four diagonal tradeoffs created in the earlier experiments. Table 4 shows the income distributions used in Experiment 3. Experiment 3 included 460 participants ( 290 women and 170 men).

Individual-level analysis of participants' behavior confirms our conjecture that more participants than was apparent in Experiment 1 use both equality and efficiency as allocation principles and make tradeoffs between them. As noted above, the design of Experiment 3 permits stricter theoretical models than Experiment 1, where we

tions, we found no significant effect when comparing the $\$ 10,000$ poverty line sample from Experiment 1 and those at the $\$ 20,000$ poverty line in Experiment 2. These results heighten our suspicion that the failure of the poverty manipulation in Experiment 1 was caused by a floor effect. 


\section{TABLE 4 Income Distributions for Experiment 3}

\begin{tabular}{|c|c|c|c|c|c|}
\hline $\begin{array}{l}21,000 \\
27,000 \\
33,000 \\
37,000 \\
42,000\end{array}$ & $1 \mathrm{st} / 5 \mathrm{th}=2.0$ & $\begin{array}{l}24,000 \\
33,000 \\
43,000 \\
51,000 \\
59,000\end{array}$ & 2.5 & $\begin{array}{l}26,000 \\
41,000 \\
60,000 \\
70,000 \\
78,000\end{array}$ & 3.0 \\
\hline $\begin{array}{l}16,000 \\
22,000 \\
28,000 \\
38,000 \\
56,000\end{array}$ & 3.5 & $\begin{array}{l}17,000 \\
28,000 \\
42,000 \\
55,000 \\
68,000\end{array}$ & 4.0 & $\begin{array}{l}19,000 \\
35,000 \\
62,000 \\
74,000 \\
85,000\end{array}$ & 4.5 \\
\hline $\begin{array}{l}12,000 \\
18,000 \\
28,000 \\
42,000 \\
60,000\end{array}$ & 5.0 & $\begin{array}{l}13,000 \\
23,000 \\
41,000 \\
61,000 \\
72,000\end{array}$ & 5.5 & $\begin{array}{l}14,000 \\
34,000 \\
63,000 \\
78,000 \\
86,000\end{array}$ & 6.1 \\
\hline
\end{tabular}

could analyze only the diagonal tradeoffs between equality and efficiency. A strict egalitarian model further restricts the earlier egalitarian model by adding to the condition that a participant must prefer the more equal to the less equal distribution in each of the four diagonal tradeoffs the further stipulation that a participant must have an equal or great preference for the more equal to less equal distribution in all of the horizontal tradeoffs. Only 9.7 percent of participants fit this model. A strict efficiency model further restricts the earlier efficiency model by adding to the condition that a participant must prefer the more efficient to the less efficient distribution in each of the four diagonal tradeoffs the further stipulation that a participant must have an equal or greater preference the more efficient to less efficient distribution in all of the horizontal tradeoffs. Only 6.3 percent of participants fit this model. (Examining participants' behavior using the less strict models used to analyze Experiment 1 reveals similar results as the earlier experiment: 36.4 percent of participants have observed behavior fitting the egalitarian model and 8.2 percent fitting the efficiency-maximization model.) The vast majority of participants therefore use both equality and efficiency as allocation principles and make tradeoffs between them.

Visual inspection of the mean ratings for the income distributions for Experiment 3 across merit conditions and separated by poverty conditions (Table 5) reveals results generally similar to those in Experiment 1. First, participants on average view both equality and ef- ficiency as normal goods. Second, there appears to be a change in absolute and relative preferences for equality and efficiency across merit conditions, with participants on average being less concerned with equality as merit level increases. Once again, however, closer analysis of these results confirms the results from Experiment 1 , including the underlying difference between the behavior of women and men. We examine these preferences using the same equality-efficiency tradeoff score and regression equations as in Experiment 1. Equality-efficiency tradeoff scores ranged from +25 , for the participant with the most extreme preference for equality, to 22 , for the participant with the most extreme preference for efficiency $(x=+5.4, s d=10.0)$.

We see at the aggregate level (Table 6a, column 1) that merit once again has a strong effect on equality-efficiency preferences in the expected direction, with participants less concerned with equality as merit level increases. Unlike Experiment 1, the poverty condition has a strong effect on equality-efficiency preferences, suggesting an independent effect of the poverty manipulation. The effect of the control variables in Experiment 3 is broadly consistent with the earlier experiment. Sex once again has a large effect, with women showing a stronger preference for equality than men. Also important is ideology, with liberals somewhat more concerned with equality than conservatives. SES did not have any significant effect on equality-efficiency preferences. Finally, as in Experiment 1, participants' independent mer- 
TABLE 5 Mean Ratings of Income Distributions in Experiment 3

\begin{tabular}{|c|c|c|c|c|c|c|c|c|}
\hline \multicolumn{9}{|c|}{$\$ 10,000$ Poverty Line Condition } \\
\hline \multicolumn{3}{|c|}{$10 \%$ Merit Condition } & \multicolumn{3}{|c|}{$50 \%$ Merit Condition } & \multicolumn{3}{|c|}{$90 \%$ Merit Condition } \\
\hline 6.03 & 7.07 & 7.66 & 5.93 & 7.11 & 7.75 & 4.86 & 6.36 & 8.16 \\
\hline 4.49 & 4.84 & 5.26 & 4.69 & 5.18 & 5.75 & 4.11 & 5.45 & 6.43 \\
\hline 2.93 & 3.05 & 3.16 & 2.70 & 3.24 & 3.45 & 2.68 & 3.96 & 4.52 \\
\hline \multicolumn{3}{|c|}{$N=76$} & \multicolumn{3}{|c|}{$N=79$} & \multicolumn{3}{|c|}{$N=80$} \\
\hline \multicolumn{9}{|c|}{$\$ 15,000$ Poverty Line Condition } \\
\hline \multicolumn{3}{|c|}{$10 \%$ Merit Condition } & \multicolumn{3}{|c|}{$50 \%$ Merit Condition } & \multicolumn{3}{|c|}{ 90\% Merit Condition } \\
\hline 6.30 & 7.51 & 7.73 & 5.74 & 6.99 & 7.94 & 5.97 & 7.17 & 7.93 \\
\hline 4.24 & 4.90 & 5.17 & 4.54 & 5.25 & 5.97 & 4.63 & 5.13 & 5.90 \\
\hline 1.83 & 2.40 & 2.94 & 2.33 & 2.38 & 2.47 & 2.41 & 2.77 & 3.01 \\
\hline \multicolumn{3}{|c|}{$N=82$} & \multicolumn{3}{|c|}{$N=70$} & \multicolumn{3}{|c|}{$N=71$} \\
\hline
\end{tabular}

\section{TABLE 6 Results of Regression Analyses for Experiment 3}

\begin{tabular}{|c|c|c|c|c|c|c|}
\hline \multirow{3}{*}{$\begin{array}{l}\text { Dependent Variable: } \\
\text { Independent Variables }\end{array}$} & \multicolumn{3}{|c|}{$\begin{array}{c}\text { A } \\
\text { Equality-Efficiency Preferences }\end{array}$} & \multicolumn{3}{|c|}{$\begin{array}{c}\text { B } \\
\text { Need Sensitivity } \\
\end{array}$} \\
\hline & \multicolumn{3}{|c|}{ Equality-Efficiency Tradeoff Score } & \multicolumn{3}{|c|}{ Need Sensitivity Score } \\
\hline & Aggregate & Women & Men & Aggregate & Women & Men \\
\hline Merit Factor $(10,50,90)$ & $\begin{array}{l}-.043^{* *} \\
(.014)\end{array}$ & $\begin{array}{l}-.051^{\star \star} \\
(.017)\end{array}$ & $\begin{array}{l}-.028 \\
(.025)\end{array}$ & $\begin{array}{l}.022^{*} \\
(.008)\end{array}$ & $\begin{array}{l}.032^{*} \\
(.010)\end{array}$ & $\begin{array}{l}.002 \\
(.014)\end{array}$ \\
\hline Poverty Factor $(0,1)$ & $\begin{array}{c}-2.83^{\star \star} \\
(.92)\end{array}$ & $\begin{array}{l}-2.45^{\star} \\
(1.13)\end{array}$ & $\begin{array}{l}-3.06 \\
(1.61)\end{array}$ & $\begin{array}{c}-2.36^{\star \star \star} \\
(.53)\end{array}$ & $\begin{array}{c}-2.19^{\star \star} \\
(.65)\end{array}$ & $\begin{array}{c}-2.32^{\star} \\
(.92)\end{array}$ \\
\hline Gender $(0=\operatorname{man} ; 1=$ woman $)$ & $\begin{array}{l}2.69 * \star \\
(.96)\end{array}$ & & & $\begin{array}{l}-.44 \\
(.58)\end{array}$ & & \\
\hline $\begin{array}{l}\text { Ideology } \\
(1-5 ; 1=\text { strong conservative })\end{array}$ & $\begin{array}{l}1.46^{*} \\
(.62)\end{array}$ & $\begin{array}{l}.906 \\
(.796)\end{array}$ & $\begin{array}{l}2.10^{*} \\
(1.03)\end{array}$ & $\begin{array}{l}-.53 \\
(.37)\end{array}$ & $\begin{array}{l}-.026 \\
(.50)\end{array}$ & $\begin{array}{c}-1.11^{*} \\
(.55)\end{array}$ \\
\hline $\begin{array}{l}\text { Mother's Education } \\
(0-5 ; 0=\text { less than high school })\end{array}$ & $\begin{array}{l}.19 \\
(.29)\end{array}$ & $\begin{array}{l}.40 \\
(.36)\end{array}$ & $\begin{array}{l}-.20 \\
(.51)\end{array}$ & $\begin{array}{l}-.075 \\
(.17)\end{array}$ & $\begin{array}{l}-.18 \\
(.21)\end{array}$ & $\begin{array}{l}.15 \\
(.30)\end{array}$ \\
\hline $\begin{array}{l}\text { Independent Merit } \\
\text { Perception }(0-100 \%)\end{array}$ & $\begin{array}{l}-.019 \\
(.023)\end{array}$ & $\begin{array}{l}-.006 \\
(.027)\end{array}$ & $\begin{array}{l}-.047 \\
(.046)\end{array}$ & $\begin{array}{l}-.015 \\
(.014)\end{array}$ & $\begin{array}{l}-.028 \\
(.016)\end{array}$ & $\begin{array}{l}.016 \\
(.025)\end{array}$ \\
\hline Constant & $\begin{array}{l}3.53 \\
(2.78)\end{array}$ & $\begin{array}{c}6.79 \\
(3.19)\end{array}$ & $\begin{array}{l}3.86 \\
(4.86)\end{array}$ & $\begin{array}{l}9.41^{\star \star \star} \\
(1.86)\end{array}$ & $\begin{array}{l}8.099^{\star \star \star} \\
(2.19)\end{array}$ & $\begin{array}{l}9.51^{\star \star} \\
(3.03)\end{array}$ \\
\hline $\begin{array}{l}\text { Adjusted R2 } \\
\text { N }\end{array}$ & $424^{.085}$ & $271^{.046}$ & $153^{.052}$ & $427^{.067}$ & $272^{.087}$ & $155^{.075}$ \\
\hline
\end{tabular}

Note: ${ }^{*} \mathrm{p}<.05,{ }^{* *} \mathrm{p}<.01,{ }^{* \star *} \mathrm{p}<.001$, two-tailed test; OLS standard errors in parentheses for equality-efficiency preference analyses and robust standard errors in parentheses for need sensitivity analyses 
it perception is not a significant predictor, further confirming that their behavior is explained by our experimental manipulation.

The surprisingly strong difference in behavior of women and men that we found in our analysis of equality-efficiency preferences in Experiment 1 is confirmed in Experiment 3. As with the earlier experiment, we divided the sample into women and men and reran the regressions (Table 6a, columns 2 and 3). The strong effect of the merit manipulation on the aggregate level is once again explained by the behavior of women alone, with women being less concerned with equality as merit level increases. The poverty condition has an independent effect on women's equality-efficiency preferences, but none of the other variables do. As for men, as in Experiment 1, the merit manipulation had no significant effect on their equality-efficiency preferences. Ideology is the only control variable that has a statistically significant effect, with liberal men more sensitive to need than conservative ones. Unlike Experiment 1, however, the poverty manipulation is weakly significant for men $(\mathrm{p}<$ .08 ), suggesting the poverty manipulation has an effect in Experiment 3 for both women and men.

Our expectation that need is a distinct allocation principle is affirmed in Experiment 3. To analyze the effect of the poverty manipulation, we use the same need sensitivity score and regression equations as in Experiment 1. First, on the aggregate level (Table 6b, column 1) we see that the poverty manipulation was successful, as revealed in the strength of the poverty condition variable on need sensitivity. The merit condition is also moderately important, with participants on average less sensitive to poverty as the degree to which income is merited increases. For women (column 2), the poverty condition is a strong predictor of need sensitivity, as in the previous experiments. Also important is the merit condition, with women's concern for need weakening when income is thought to be increasingly merited. For men (column 3 ) the poverty condition is also a significant predictor of need sensitivity, unlike in the previous experiments. So, too, is ideology, with liberal men more concerned with need than conservative ones. These results, combined with those from Experiment 2, provide us with considerable evidence that need is a distinct allocation principle.

\section{Discussion}

We wish to summarize our findings and discuss how our results concerning gender in particular relate to research on the gender gap in other areas of political inquiry. Be- fore discussing our results, however, we should address the possible limits to their generalizability. Like most experimental research, we used a convenience sample of undergraduates, raising legitimate questions about external validity (see Sears 1986). We did make our subject pool as diverse as possible, partly through using an unusually large sample and partly through our choice of test site. One of our test sites, the University of Houston, is quite diverse (over 50 percent minority students). We nonetheless cannot claim to have a representative sample. Most notably, our subject pool is heavily skewed in terms of age. Based on national survey data, we know that younger respondents are more oriented toward equality, and so it is quite plausible that a more representative sample would show participants less oriented to equality than our results suggest. Whatever the limits of external validity, however, our first concern was internal validity. Our primary aim was to examine the relationship among allocation principles and to see how they changed when we manipulated theoretically relevant conditions. By manipulating crucial variables between participants, we are able to test these principles without alerting participants to our interest in these questions. We included a rigorous manipulation check to guarantee that only participants who received the experimental treatment were included. Likewise, by asking participants in the post-experimental questionnaire about their own perceptions of the relationship between merit and income, and then entering that information as an independent variable in our analyses, we are able to determine that our experimental manipulations rather than participants' pre-existing perceptions explain our results. This test shows how using multiple regression analysis to enter additional controls can strengthen experimental research. The success of these safeguards combined with the inherent strengths of experimental research (see Kinder and Palfry 1993) make us confident that we have strong internal validity and that further research to confirm and extend our results would be fruitful.

\section{Allocation Principles in Distributive Justice Judgments}

We found that all of the allocation principles we studyequality, efficiency, merit, and need-play a distinct role in distributive justice judgments. We also found that most individuals use all or most of these principles simultaneously in making judgments rather than applying different norms in separate "spheres." Finally, we observed that individual characteristics influence how they weigh these principles. Most strikingly, we found an unexpectedly strong sex difference in the use of these principles. 
Equality. Equality performed as a normal good with participants overwhelmingly preferring more equality over less while holding efficiency constant. Furthermore, the general trend of participants shows a strong desire for equality even at the cost of a considerable loss in efficiency. This finding strongly reaffirms Mitchell et al.'s (1993) results and suggests that equality plays a stronger role than Frohlich and Oppenheimer (1992) found.

Efficiency. Efficiency also performed as a normal good, more was consistently and overwhelmingly preferred to less, when holding other factors constant. We found individuals use both equality and efficiency as allocation principles and make tradeoffs between them. Our results accord with Okun's (1975) influential framework for public policy analysis. Our findings concerning the factors influencing individuals' equality and efficiency preferences partially confirm previous research, but also suggest a more complex picture than earlier studies, especially concerning sex.

Merit. Our aggregate-level results initially appeared to suggest that all individuals are less concerned with equality as the degree to which income is merited increases, confirming the results of Mitchell et al.'s (1993) study. Upon closer inspection, however, we discovered the results were driven entirely by women. Men's equality-efficiency preferences were not influenced by merit assumptions, but instead by ideology, which was not a statistically significant predictor for women. Our findings arguably support both sides of the debate over whether merit is a valid moral allocation principle, but that support is unexpectedly divided along gender lines that philosophers - and many empirical researchers - do not usually consider.

Need. One of our principal aims was to determine whether need is a distinct allocation principle. We found that need is a distinct principle, but we also saw that sensitivity to need can be difficult to distinguish from a concern about inequality. Need can be defined either absolutely, as we did, or relatively. Defined relatively, sensitivity to need is difficult to distinguish from concern for inequality or relative deprivation. Participants in our study consistently exhibited a low preference for low-equality distributions, and much of their need sensitivity seems to have been obscured by their concern for inequality. Only when we sufficiently distinguished need and inequality in our experimental design did we find a consistently distinct concern for need. We found that women are more sensitive to need than men, consistent with earli- er research, but we also found that concern for need was mediated by merit assumptions among women alone. Also consistent with earlier research, we found some evidence that political ideology influences need sensitivity, with conservatives on average less concerned with need than liberals.

Finally, before turning to socio-psychological and other explanations for the gender differences we have found, we must consider the possibility that our results are due in part to the specific tradeoffs used in our experimental design. While the influence of merit assumptions on equality-efficiency preferences was not statistically significant for men, the direction of the change in those preferences was consistent with the statistically significant change in women's preferences. We may not have been able to see the influence of merit on equality-efficiency preferences among men because of the range of equality and efficiency levels we used in our design. An altered design that increased the cost of trading off equality for efficiency might reveal the influence of merit assumptions among men where their preference for marginal increases in efficiency was weaker. That we found such clear gender differences, and the fact that the differences we found were not inconsistent with previous findings in justice research, nonetheless suggests we must entertain other explanations.

\section{The Gender Gap in Distributive Justice Judgments}

Certainly our most surprising and potentially most interesting results regard differences in how women and men use allocation principles in distributive justice judgments. Based on earlier research, we expected to see differences between women and men concerning their relative preferences for equality and efficiency and their sensitivity to need. We did see such results, but we also discovered gender differences that went well beyond these ,relative preferences. In particular, we found unexpected gender-specific interactions of merit with the other allocation principles. We saw that women's equality-preferences were mediated by merit assumptions, but that men's were not. These findings are in some tension with other research on gender differences regarding merit beliefs. For example, Major, Bylsma, and Cozzarelli (1989) find in work domains men tend to distribute rewards using merit while women emphasize equality (see also Major and Adams 1983). While suggestive, our studies differ sufficiently to make it difficult to draw any strong conclusions regarding the compatibility of results. Likewise, we found that women's sensitivity to 
need was mediated by merit assumptions whereas men's were unaffected. Our research was not designed to explore these effects since we did not anticipate these gender-specific interactions. Nor does previous justice research offer guidance in interpreting the results. We can nonetheless consider several explanations that have been offered for gender gaps observed in political and policy preferences.

Two leading theories have been advanced for gender differences found in political, social, and moral behavior and attitudes. The first is gender socialization, the best known version of which is Gilligan's (1982) "different voice" theory. She argues that women emphasize an ethic of "care and connection" while men tend to embrace an "ethic of rights" that stresses individualism. On the one hand, our finding that women are more sensitive to need than men generally accords with her position. On the other hand, our results concerning merit seem to run contrary to her theory since, based on what she does argue, one would probably expect men and not women to distribute according to merit. The fact that women's equality-efficiency preferences were mediated by merit assumptions, however, suggests a sensitivity to context in moral reasoning that Gilligan argues is more typical of women.

The other leading explanation for gender differences emphasizes structural or situational differences between women and men in society. This explanation points to women's traditional socioeconomic position and suggests their tendency to weigh social welfare issues more heavily than men is the result of their vulnerability relative to men (e.g., Piven 1985). In terms of our experiment, women's socioeconomic position might explain why they weigh need and equality more heavily than men. While this theory may explain the intercept effects we find, it does not explain the interaction effects we find between gender and the use of these principles in relation to merit assumptions. Gender socialization and socioeconomic theories require further testing before the underlying reason for such gender differences is clear.

Recent research into the gender gap observed in political and policy preferences over the past two decades provides somewhat more guidance in interpreting our own findings. There are two basic approaches to explaining the gender gap in voting and party preferences. The first approach focuses on attitude differences, arguing that the gender gap stems from underlying differences in political attitudes that are politicized in similar ways. The second approach emphasizes possible differences in how women and men weigh certain issues, suggesting that the gender gap is explained better by different levels of salience of political issues for women and men. Both approaches have received some empirical support (see Kaufman and Petrocik 1999), but the second approach is more relevant to our research since we also find basic differences in how women and men weigh allocation principles. Early studies of the different weights that women and men assign to political issues found that men tend to weigh military issues more heavily and that women tend to give greater weight to social issues (Gilens 1988; see Shapiro and Mahajan 1986). Our results are generally in line with these findings, insofar as we observe women being more sensitive to need and equality, which are principles analogous to the social issues examined in the gender gap research. Perhaps more suggestive, research into gender differences in economic policy preferences has suggested that women tend to vote more sociotropically and men more egoistically (Welch and Hibbing 1992; Chaney, Alvarez, and Nagler 1998). This finding may be analogous to the difference we find between women and men concerning the interaction between merit and equality-efficiency preferences. Interpreted in this light, women in our study were behaving more sociotropically, reacting to the information about the degree to which merit is said to predict income in society as a whole, and men were behaving more egoistically, with their equality-efficiency preferences determined by their individual ideological beliefs. This parallel is weakened by the fact that our study examined impartial, and not self-interested, judgments and preferences. The difference in how women and men reason about distributive justice that we found nonetheless parallelsand may even underlie-the gender gap seen in political and policy preferences.

\section{Conclusion}

We have found that distributive justice norms are complex yet structured. The fact that individuals use several distinct allocation principles simultaneously in distributive decisions makes their behavior necessarily complex. This complexity is nonetheless comprehensible, both because the underlying theoretical relationship among these allocation principles is structured and because the independent factors that influence how individuals use these principles are predictable. The gender difference we find in how individuals use and weigh allocation principles in particular raises new questions for justice research to explore. The theoretical relationships we find among allocation principles should be of interest to political and moral theorists, and our empir- 
ical findings should be considered when thinking about the philosophical validity of justice theories as well as their practical application. Our findings also provide a grounding for more theoretically informed empirical investigations of political attitudes and behavior. If we are interested in individuals' opinions on the distribution of society's benefits and burdens, we need appropriate stimuli for eliciting meaningful responses and understanding their views in their full complexity. In making political, social, and moral decisions women and men are concerned in part with justice, and our research is a step toward understanding distributive justice norms in theory and practice.

\section{Appendix Participant Instructions}

Portions printed in italics are varied between-subject. The first selection specifies the degree to which income is explained by effort and ability ( 10 percent, 5'0 percent, 90 percent), while the other selections specify the level of the poverty line $(\$ 10,000$ and $\$ 15,000)$.

\section{Assessment of Income Distributions}

Please read the description below. Please ask if you have any questions at any time.

Imagine that you are an outside advisor to the country described below. You are not a member of the country. You are being asked to give your opinion on what policies would be best for the country. We are interested in your ideas about how income should be distributed when your own interests are not at stake.

Country D is a self-governed society made up of people of a variety of racial and ethnic backgrounds. There is a broad variety of occupations in the society. Scientific studies have demonstrated that the amount of income a person receives in Country D is due almost entirely to the person's effort and ability. People who are willing to work hard, take some risks, and acquire the proper education and skills have a very good chance of having a higher income. On the other hand, people who are not willing to do these things have a very good chance of having a lower income. The amount of income a person receives is $90 \%$ due to his or her effort and ability, and only $10 \%$ due to luck, connections, and similar factors.

The people of Country D are considering a number of policies for their society. Economic studies have demonstrated what effects the different policies will have on the average income in the country as a whole and on differences in people's income (income distribution). Backers of the different policies are convinced by these studies and do not disagree about the effects of the policies. They do disagree on which policy is the best for their country. Among other considerations, certain analysts are more concerned about the average income, while others are more concerned about equality of income.

You are being asked to give your opinion about how good the different policies would be for Country D based on their effects on income.

In order to evaluate these different policies, you will be presented with charts that show their effects on income. The charts show family incomes broken down into each quintile (20 percent) of families, from the poorest 20 percent of families up to the wealthiest 20 percent. The charts also give you information about:

- the average income in the country as a whole;

- the poverty line (the amount of income needed to provide for the basic needs of food, housing, clothing, and medical care for a four-person family). The poverty line in Country D is $\$ 15,000$.

- the income inequality ratio, a commonly used measure of income inequality. The ratio tells you how many times greater the income of the wealthiest 20 percent of families is compared to the poorest 20 percent of families. For example, if the wealthiest 20 percent earn $\$ 100,000$ and the poorest 20 percent earn $\$ 20,000$, then the wealthiest 20 percent earn 5.0 times more income than the poorest 20 percent, making the income inequality ratio 5.0. The higher the income inequality ratio, the more unequal incomes are; the lower the income inequality ratio, the more equal incomes are.

All the income figures are for after tax income for fourperson families. All income figures are in U.S. dollar equivalents.

The chart below shows what effects a hypothetical plan, Plan Z, would have on income for Country D. Average family incomes after taxes are: $\$ 18,000$ per year for the poorest .20 percent of families, $\$ 26,000$ for the next 20 percent, $\$ 34,000$ for the next 20 percent, $\$ 50,000$ for the next 20 percent, and $\$ 72,000$ for the wealthiest 20 percent. The average family income for the country as a whole is $\$ 40,000$. The poverty line is $\$ 15,000$. The income inequality ratio is 4.0 .

\section{References}

Adams, J. S. 1965. "Inequity in Social Exchange." In Advances in Experimental Social Psychology, ed. L. Berkowitz. New York; Academic Press.

Alves, W. M., and Rossi, P. H. 1978. "Who Should Get What? Fairness Judgments of the Distribution of Earnings." American Journal of Sociology 84:541-564.

Alwin, Duane F, Galin Gornev, and Ludmila Khakhulina. 1995. "Comparative Referential Structures, System Legitimacy, and Justice Sentiments: An International Comparison." In Social Justice and Political Change, ed. James R. Kluegel, David S. Mason, and Bernd Wegener. New York: Aldine.

Aristotle. 1985. Nicomachean Ethics. Trans. Terence Irwin. Indianapolis: Hackett.

Barry, Brian. 1995. Justice as Impartiality. Oxford: Oxford University Press.

Boulding, Kenneth E. 1962. "Social Justice in Social Dynamics.” In 
Social Justice, ed. R. B. Brant. Englewood Cliffs, N.J.: Prentice Hall.

Braybrooke, David. 1987. Meeting Needs. Princeton: Princeton University Press.

Chaney, Carole Kennedy, R. Michael Alvarez, and Jonathan Nagler. 1998. "Explaining the Gender Gap in U.S. Presidential Elections, 1980-1992." Political Research Quarterly 51:311-339.

Dahl, Robert A. 1989. Democracy and Its Critics. New Haven: Yale University Press.

Davidson, Pamela, Susanne Steinmann, and Bernd Wegener. 1995. "The Caring But Unjust Women?" In Social Justice and Political Change, ed. James R. Kluegel, David S. Mason and Bernd Wegener. New York: Aldine.

Deutsch, Morton. 1975. "Equity, Equality, and Need: What Determines Which Value Will Be Used as the Basis for Distributive Justice?" Journal of Social Issues 31:137-149.

Deutsch, Morton. 1985. Distributive Justice. New Haven: Yale University Press.

Elster, Jon. 1995. "The Empirical Study of Justice." In Pluralism, Justice, and Equality, ed. David Miller and Michael Walzer. Oxford: Oxford University Press.

Friedman, Milton. 1963. Capitalism and Freedom. Chicago: University of Chicago Press.

Frohlich, Norman, and Oppenheimer, Joe A. 1992. Choosing Justice: An Experimental Approach to Ethical Theory. Berkeley: University of California Press.

Gilens, Martin. 1988. "Gender and Support for Reagan: A Comprehensive Model of Presidential Approval." American Journal of Political Science 32: 19-49.

Gilligan, Carol. 1982. In a Different Voice. Cambridge: Harvard University Press.

Hayek, Friedrich. 1976. Law, Legislation, and Liberty. Vol. II: The Mirage of Social Justice. London: Routledge.

Hegtvedt, Karen A,, and Cook, Karen S. 1999. "Distributive Justice: Recent Theoretical Developments and Applications." In The Justice Reader, ed. Joseph Sanders and Lee Hamilton. New York: Plenum

Hochshild, Jennifer L. 1981. What's Fair? American Beliefs About Distributive Justice. Cambridge: Harvard University Press.

Kaufman, Karen M., and Petrocik, John R. 1999. "The Changing Politics of American Men: Understanding the Sources of the Gender Gap." American Journal of Political Science 43:864-887.

Kinder, Donald R., and Palfrey, Thomas R. 1993. "On Behalf of an Experimental Political Science.” In Experimental Foundations of Political Science, ed. Donald R. Kinder and Thomas R. Palfrey. Ann Arbor: University of Michigan Press.

Kluegel, James R., and Masaru Miyano. 1995. "Justice Beliefs and Support for the Welfare State in Advanced Capitalism." In Social Justice and Political Change, ed. James R. Kluegel and Eliot Smith. New York: Aldine.

Kluegel, James R., and Smith, Eliot. 1986. Beliefs About Equality: Americans' Views of What is and What Ought to Be. New York: Aldine.

Kluegel, James R., David S. Mason, and Bernd Wegener. 1995. Social Justice and Political Change. New York: Aldine.

Lane, Robert. 1962. Political Ideology. New York: Free Press.
Lissowski, Grzegorz, and Swistak, Piotr. 1995. "Choosing the Best Social Order: New Principles of Justice and Normative Dimensions of Choice." American Political Science Review 89:74-96.

Locke, John. [1689] 1988. Two Treatises of Government. Ed. Peter Laslett. Cambridge: Cambridge University Press.

Major, Brenda, and Adams, Jeffrey B. 1983. "Role of Gender, Interpersonal Orientation, and Self-Presentation in Distributive-Justice Behavior." Journal of Personality and Social Psychology 45:598-608.

Major, Brenda, Wayne H. Bylsma, and Catherine Cozzarelli. 1989. "Gender Differences in Distributive Justice Preferences: The Impact of Domain.” Sex Roles 21:487-497.

Major, Brenda, and Deaux, Kay. 1982. "Individual Differences in Justice Behavior." In Equity and Justice in Social Behavior, ed. L. Berkowitz and G. W. Walster. New York: Academic Press. [actually edited by Jerald Greenberg and Ronald L. Cohen]

Marmor, Theodore R., Jerry L. Machaw, and Philip L. Harvey. 1990. America's Misunderstood Welfare State. New York: Basic Books.

McClosky, Herbert, and Zaller, John. 1984. The American Ethos: Public Attitudes Toward Capitalism and Democracy. Cambridge: Harvard University Press.

Mellers, Barbara A. 1982. "Equity Judgment: A Revision of Aristotelian Views." Journal of Experimental Psychology, General 111:242-270.

Messick, D. M., and Cook, Karen S., ed. 1983. Equity Theory. New York: Praeger.

Miller, David. 1991. "Recent Theories of Social Justice," British Journal of Political Science 21:371-391.

Miller, David. 1999. Principles of Social Justice. Cambridge: Harvard University Press.

Mitchell, George, Philip E. Tetlock, Barbara A. Mellers, and Lisa Ordóñez. 1993. "Judgments of Social Justice: Compromises Between Equality and Efficiency." Journal of Personality and Social Psychology 65:629-639.

Nozick, Robert. 1974. Anarchy, State, and Utopia. New York: Basic Books. Okun, Arthur. 1975. Equality and Efficiency: The Big Tradeoff: Washington, D.C.: Brookings Institute.

Ordóñez, Lisa, and Mellers, Barbara A. 1993. "Tradeoffs in Fairness and Preference Judgments." In Psychological Perspectives on Justice: Theory and Applications, ed. Barbara Mellers and Jonathan Baron. Cambridge: Cambridge University Press.

Piven, Frances F. 1985. "Women and the State: Ideology, Power, and the Welfare State." In Gender and the Life Course, ed. Alice S. Rossi. New York: Aldine.

Plattner, Marc F. 1979. "The Welfare State vs. The Redistributive State." The Public Interest 55:28-48.

Posner, Richard A. 1981. The Economics of Justice. Cambridge: Harvard University Press. Rae, Douglas. 1981. Equalities. Cambridge: Harvard University Press.

Rasinski, Kenneth A. 1987. "What's Fair is Fair-Or is it? Value Differences Underlying Public Views About Social Justice.” Journal of Personality and Social Psychology 53:201-211.

Rawls, John. 1971. A Theory of Justice. Cambridge: Harvard University Press.

Sandel, Michael. 1982. Liberalism and the Limits of Justice. Cambridge: Cambridge University Press. 
Schwinger, Thomas. 1980. "Just Allocation of Goods: Decisions Among Three Principles." In Justice and Social Interaction: Experimental and Theoretical Contributions from Psychological Research, ed. Gerald Mikula. Bern: Hans Huber.

Schumpeter, Joseph A. 1947. Capitalism, Socialism, and Democracy. 2nd ed. New York: Harper.

Sears, David 0. 1986. "College Sophomores in the Laboratory: Influence of a Narrow Data Base on Social Psychology's View of Human Nature." Journal of Personality and Social Psychology 5 1:515-530.

Sen, Amartya. 1992. Inequality Reexamined. Cambridge: Harvard University Press.

Sen, Amartya. 1997. On Economic Inequality. Enlarged edition. Oxford: Oxford University Press.

Shapiro, Robert Y., and Mahajan, Harpreet. 1986. "Gender Differences in Policy Preferences: A Summary of Trends from the 1960s to the 1980s." Political Opinion Quarterly 50:42-61.

Sher, George. 1987. Desert. Princeton: Princeton University Press. Skitka, Linda J., and Tetlock, Philip E. 1992. "Allocating Scarce Resources: A Contingency Model of Distributive Justice.” Journal of Experimental Social Psychology 28:1205-1223.

Skitka, Linda J., and Tetlock, Philip E. 1993. "Of Ants and Grasshoppers: The Political Psychology of Allocating Public Assistance." In Psychological Perspectives on Justice: Theory and Applications, ed. Barbara Mellers and Jonathan Baron. Cambridge: Cambridge University Press.

Swift, Adam, Gordon Marshall, Carole Burgoyne, and David Routh. 1995. "Distributive Justice: Does It Matter What the People Think?" In Social Justice and Political Change, ed. Barbara Mellers and Jonathan Baron. New York: Aldine.
Temkin, Larry S. 1993. Inequality. Oxford: Oxford University Press.

Tetlock, Philip E., and Mitchell, Gregory. 1993. "Liberal and Conservative Approaches to Justice: Conflicting Psychological Portraits." In Psychological Perspectives on Justice: Theory and Applications, ed. Barbara Mellers and Jonathan Baron. Cambridge: Cambridge University Press.

Törnblom, Kjell Y. 1992. "The Social Psychology of Distributive Justice.” In Justice: Interdisciplinary Perspectives, ed. Klaus R. Scherer.

Tyler, Tom R., Robert J. Boeckmann, Heather J. Smith, and Yuen J. Huo. Social Justice in a Diverse Society. 1997. Boulder: Westview.

Verba, Sidney, Steven Kelman, Gary R. Orren, Ichiro Miyake, Joji Watanuki, Ikuo Kabashima, and G. Donald Ferree, Jr. 1987. Elites and the Idea of Equality: A Comparison of Japan, Sweden, and the United States. Cambridge: Harvard University Press.

Verba, Sidney, and Orren, Gary R. 1985. Equality in America: The View from the Top. Cambridge: Harvard University Press.

Walzer, Michael. 1983. Spheres of Justice: A Defense of Pluralism and Equality. New York: Basic Books.

Weale, Albert. 1985. "The Welfare State and Two Conflicting Ideals of Equality." Government and Opposition 20:315-327.

Weatherford, M. Stephen. 1992. "Measuring Political Legitimacy." American Political Science Review 86: 149-166.

Welch, Susan, and Hibbing, John. 1992. "Financial Conditions, Gender, and Voting in American National Elections." Journal of Politics 54: 197-213. 